\title{
Developing a Framework to Guide Digital Business Transformation
}

\author{
Kabaly Pitchakannu Subramanian, Rengarajan Veerasamy \\ Arab Open University, Sultanate of Oman
}

\begin{abstract}
Digital technologies are shaping business landscape. Digital business transformation is becoming a critical phenomenon in sustaining the competitive advantage. There is a need for frameworks to guide the digital business transformation initiatives of organizations. There are few academicbased and industry-based research reported on Digital business transformation. There are evidences that there is a lack of alignment between industry-based research and academic-based research about digital business transformation. This paper applies a mixed approach of both academic and practitioner's perspectives in building a framework to guide Digital Business Transformation and that contributes to improving a general understanding of this phenomenon. This research is conducted in the context of growing appetite for digital business transformation in Gulf states, particularly Sultanate of Oman. A mixed approach of desk research and interview method was used in this research. Various conceptual and theoretical frameworks related to digital business transformation were identified, studied and discussed with the practitioners for their input based on their practical experience of leading digital transformation initiatives at their respective organizations which led to a guiding framework for digital business transformation. The research findings have significant impact on the organizational transformation enabled by digital technologies and its transformative effect on businesses and Societies through digitization, digitalization and digital transformation.
\end{abstract}

Keywords: Competitive advantage; Digitalization; Digitization; Guiding framework; Organizational transformation. 